\title{
Employers' responses to the HIV epidemic in sub-Saharan Africa: Revisiting the evidence
}

Kevin Deane ${ }^{1}$, Sara Stevano ${ }^{2}$, Deborah Johnston ${ }^{3}$

\section{Abstract}

Do employers have a role to play to support people living with HIV? The literature on sub-Saharan Africa points to the existence of a positive business case that sees firms as incentivised to provide HIV-related services to HIV positive workers ${ }^{4}$. However, the evidence is narrow and incomplete, with the business case holding for a limited number of formal sector skilled workers, leaving out the majority of people living with HIV. If employers are to play a role, policy makers need to create conducive conditions for positive responses, in addition to - not in replacement of - strengthening public health care systems.

Key words

Keywords: HIV, employment, workplace programmes, discrimination, private sector

\section{Introduction}

Over the last decade, the focus of the global HIV/AIDS community has experienced a tangible shift away from prevention activities towards a new paradigm in which expanding access to treatment has gained paramount importance, and is central to the recently announced UNAIDS 90-90-90 goals (UNAIDS, 2014). This is in part due to new evidence on the efficacy of biomedical interventions such as the provision of Antiretorviral Therapy (ART), which suggests that HIV positive individuals in both the global north and the global south, if adherence to the daily drug regimes is possible, can expect to live a normal life-span (May et al., 2014; Mills et al., 2011). Further, recent evidence also suggests that extension of ART provision to all individuals in infected communities, including those who are not HIV positive, can significantly reduce transmission rates (Cohen et al., 2011). This has provided further, though not uncontested (Macklin \& Cowan, 2012; Nguyen, Bajos, Dubois-Arber, O'Malley, \& Pirkle, 2011), impetus to the treatment expansion agenda. This is reflected in the rapid expansion of treatment coverage across the globe, and in particular in sub-Saharan Africa which has seen the

\footnotetext{
${ }^{1}$ Faculty of Business and Law, University of Northampton, UK. Corresponding author. Email: Kevin.Deane@northampton.ac.uk

${ }^{2}$ University of the West of England, UK

${ }^{3}$ SOAS, University of London, UK

${ }^{4}$ The term 'HIV positive' will be used in this article following UNAIDS terminology guidelines
} 
number of people accessing ART rise from less than 100,000 in 2003 to over 10.5 million in 2014, a coverage rate of around $41 \%$, and a 100 -fold increase in just over a decade (WHO, 2016).

One of the implications of the biomedical evidence related to the normal life-span that HIV positive individuals who access treatment can expect to have is that this has begun to change the way that the disease is framed, from a life-threatening disease that is essentially an extended death sentence, to a condition that can be managed, lived with, and aged with. As a result, gaining an understanding of individual's experience of living with the virus is central to the management of the epidemic as a long-wave event (Abrahams \& Jewkes, 2012; dos Santos, Kruger, Mellors, Wolvaardt, \& van der Ryst, 2014). A key aspect that has gained attention in the literature is the ability of those living with HIV to access employment opportunities, while receiving adequate care and without shifting the burden onto other household members (Cramer, Oya, \& Sender, 2008; Mueller, 2011).

International donors have prioritised HIV treatment over funding to address other diseases (Gideon \& Porter, 2016; Hunsmann, 2016). Within this wave of treatment expansion, some have critically considered the role of national and local governments, NGOs and communities to deliver treatment to the people who need it (Ann Richey, 2012; Boesten, 2011; Knutsson, 2016). Another stream of literature is concerned with employers' responses to HIV and AIDS due to the potential economic impact of the epidemic on profits and productivity at the firm-level and also employment levels and working conditions (Bolton, 2008; Rosen, Feeley, Connelly, \& Simon, 2007). These studies also contribute to build the vision of the workplace as a site for the expansion of ART coverage, thus tapping into donors' treatment push, and also offering an alternative pathway to enhancing treatment coverage in the light of weakened public healthcare systems. These dual concerns are seen as complementary, a win-win scenario in which 'ARV [AntiRetroViral] treatment can be cost saving for industry and life-saving for workers' (Eholie et al., 2003, p1). Attempts to convince firms that offering workplace programmes to support HIV positive workers is not just a socially responsible and ethical course of action but also good for business have gained currency, thus contributing to what some have called instrumentalist approaches to health and well-being (Gideon \& Porter, 2016).

This purported win-win scenario is not without its critics, who point to examples of other less supportive practices. In stark contrast to the narrative of supportive workplace programmes, firms are accused of implementing measures to help them avoid the costs associated with the epidemic by 'shifting the burden' onto their employees, households and governments (Rosen \& Simon, 2003; Vass 2003). These measures can take the form of direct discriminatory practices to exclude HIV positive individuals from entering the workforce, through pre-employment screening, or to create barriers for HIV positive workers thus pushing them out of the workforce, through restrictions and reductions of healthcare benefits, denial of progression and promotion, and job 
termination. Other strategies that contribute to shifting the burden include changes in employment contracts and increasing casualisation of the workforce, the outsourcing of low-skilled jobs, the adoption of more capital-intensive production techniques to replace workers, and the return to more labour-intensive systems of production which rely on cheap and easily-replaced labour (Bujra, 2004; Ramachandran, Shah, \& Turner, 2007; Rosen \& Simon, 2003; Simon, Rosen, Whiteside, Vincent, \& Thea, 2000; Sprague, Simon, \& Sprague, 2011).

This article reviews and critically reconsiders the literature on the response of employers and the economic impact of the HIV epidemic on firms, and engages with these contrasting strategies that are presented in the literature. We do this by firstly reviewing the literature on the business case for the positive response, and the evidence base that is supportive of this approach. We then critically reappraise this evidence on its own terms, as well as identifying a range of omissions and tensions between the contexts in which the business case appears to hold and the more general employment conditions of most workers in sub-Saharan Africa. Following this, we reflect on a range of conceptual and methodological limitations of the business case approach and underlying economic model, before highlighting some evidence gaps and methodological challenges that relate to a future research agenda. We contribute to the literature on this issue by presenting a new and critical assessment of the positive response both empirically and methodologically, confirming and extending existing critiques as well as developing the theory of the firm's decisionmaking processes in relation to HIV.

Our findings are at odds with much of the literature on win-win scenarios as we find the evidence, when examined in more detail, is less compelling than is often portrayed. This is due to a number of conceptual and methodological shortcomings, that include the failure to take into account how the business case varies with a range of dimensions, including the skill level of workers, firm sector, firm size, HIV prevalence within the firm and the general background prevalence and the type of employment contracts that workers are on (Johnston, 2013), and other issues that relate to the cost-benefit analysis approach typically employed to justify positive interventions. We conclude that the positive view of a private sector-led response to the HIV epidemic is questionable at best.

\section{The business case for a 'positive' response}

A stream of literature suggests that firms have an important and positive role to play in the provision of medical and social support for workers living with HIV. The justification for employers to respond in a 'positive' way (Law, 2008) through the implementation of workplace treatment and care programmes, beyond ethical or humanitarian grounds, is framed by the economic impact of the 
epidemic on firms, in which a business case is constructed by weighing up the economic costs of having a certain proportion of HIV positive workers against the costs of the workplace programme itself. Whilst other factors, including the role that employment can play in terms of supporting access and adherence to treatment (ILO, 2013), suggest that the workplace can be an important site for expanding treatment coverage, the business case approach remains the main mechanism through which employers are to be persuaded that doing so is in their own interests.

The firm's costs associated with having a number of HIV positive employees have been variously identified as: the reduced productivity of both HIV positive workers and the workforce as a whole, increased absenteeism, increased overtime payments, a negative impact on labour force morale, the payment of pension, funeral and other health benefits should workers leave, retire or die (if such benefits are in place), high workforce turnover, the costs of recruiting and training replacement workers, the lost skills and experience to the workforce, costs incurred while new workers get up to speed, and less tangible costs such as reduced investor confidence (Bolton, 2008; Law, 2008; Rosen et al., 2004; Simon, et al., 2000). On the other hand, workplace programmes entail costs that need to be sustained by firms. Depending on the type of package offered, the costs typically include employee's time, external training/education/awareness activities, materials needed for prevention, internal surveys to document HIV prevalence, the provision of general healthcare services and the funding of ART and other related treatment (Simon, et al., 2000). Whilst in practice workplace programmes are extremely heterogeneous, involving different mixes of prevention and treatment activities and a range of delivery methods, broadly speaking these strategies can be viewed together as an attempt to address the issue of HIV in a positive way.

Estimations based on this cost-benefit analysis approach suggest that there is a compelling business case for taking positive action, and large, quantifiable costs avoided by doing so, both at the firm level and for individual workers. For example, an early study that evaluated the economic benefit of the provision of ARV's in a firm in Cote D'Ivoire estimated savings of US\$287,000 due to reduced absenteeism, US\$294,000 related to health care costs and US\$194,000 in funeral costs (Eholie, et al., 2003). These claims are repeated by a number of companies in various guises; Anglo American reported that there was a 70-cent return over the first 12 months on every dollar spent for employee treatment with antiretroviral drugs (Bolton, 2008), BHP Billiton reported that 'for every dollar it invests in HIV training, education and medical programmes, the return is four-fold in savings for re-training, absenteeism and productivity' (Law, 2008), and a study of seven companies in Zambia estimated that typical savings of workplaces programmes in 2007 were approximately US\$500,000 (Ilon, Barwise, Hüsken, \& Tembo, 2007). More recently, dynamic modelling of data from a mining firm in South Africa finds that scaling up access to testing and counselling services coupled 
with ARV provision leads to a saving of around US\$950,000 per year (Meyer-Rath et al., 2015). In this study, the source of these benefits are due to significant and sustained improvements in patients who were enrolled in an ART programme with regards to the fatigue they suffered, their ability to perform normal tasks, increased rates of employment, and reductions in difficulties with job performance experienced by those in work (Rosen et al., 2014), reflecting both increasing workforce participation and, crucially, improved productivity at work. As a result, there is an increasing emphasis on more precisely quantifying the economic benefits of workplace programmes, accounting for the significant impact on productivity observed in HIV positive workers who have access to treatment and thus going beyond the standard framework which concentrates on costs 'avoided', documenting the challenges and barriers to the uptake and success of workplace programmes, as well as identifying best practice to support expanded implementation across the private sector (AIDS Accountability International \& Rosencrantz and Co, 2011; George, 2006; ILO, 2015; Scott et al., 2013; UNAIDS, 2002). With ARVs increasingly (though in some cases intermittently) provided free at the point of access in many sub-Saharan countries, the business case may be further enhanced if costs of treatment are removed from estimates of the costs of workplace programmes.

\section{Reassessing the evidence of the positive case}

Despite the seemingly compelling case for firm intervention, the general consensus is that the response of firms and employers to the issue of HIV has been weak, with low coverage of workplace programmes in their various guises and/or formal HIV company policies reported in a number of surveys and studies conducted in sub-Saharan Africa (Bendell, 2003; Kironde \& Lukwago, 2002; Mahajan, Colvin, Rudatsikira, \& Ettl, 2007; Ramachandran, et al., 2007). This can be partially explained by several key factors. Firstly, a closer look at the evidence suggests a more complex and nuanced picture, with the business case for intervening in a positive way and providing workplace programmes often less compelling than is generally acknowledged. For example, Rosen et al. (2004) estimate that within six formal sector enterprises located in South Africa and Botswana, the cost of having between 7.95 to $25 \%$ of HIV positive workers, which are relatively high rates of HIV, ranged from 0.4 percent to $5.9 \%$ of those workers' wages, which as a share of total operating costs ranged from $0.0001 \%$ to $0.62 \%$. Whilst the authors note that their estimates are conservative and also reflect the capital intensive nature of the firms surveyed, this highlights that the costs of the epidemic to firms may not be as severe as is often portrayed. Other evidence also challenges the sort of figures quoted above which make strong claims about the viability of workplace programmes, with Habyarimana et al. (2010) estimating that for the typical African manufacturing firm, based on 
panel data from a Botswanan mining company, the benefits (costs avoided) of providing treatment to workers covers only 8-22 percent of the cost of treatment (Habyarimana, Mbakile, \& Pop-Eleches, 2010).

Secondly, despite the sound-bites offered by the proponents of workplace programmes (Brink \& Pienaar, 2007), it is not clear that they even work in practice (Connelly \& Rosen, 2008). Whilst there are examples of workplace programmes that have succeeded in rapidly scaling up access to treatment and even reducing HIV prevalence within the workforce (UNAIDS 2002), in general the broader evidence suggests that the impact of workplace programmes is limited. For example, in a recent review by the ILO that focused on showcasing lessons from best-practice workplace programmes, it was acknowledged that no solid evidence existed on the achievement of some key outcomes that included increased take-up of ART and other treatment services by employees (see also (George, 2006) for a discussion of this), reduced costs (including recruitment, supervision, training and lost productive time) and increased productivity (ILO, 2015), outcomes which are intimately linked to both the studies that use the business case approach and also the broader role of firms in expanding access to treatment to support global targets around treatment coverage (UNAIDS, 2014). The conclusions from the ILO's wide-ranging review seem to contradict the view that workplace programmes can help avoid the types of costs that are associated with HIV positive workers and that are central to the methodology underpinning the 'business case' approach.

Finally, there is a regional bias and focus to the evidence, which is dominated by case studies originating from South Africa (Setswe, 2009). This in part reflects the sectoral focus mentioned in the introduction and discussed in more detail below, but is also related to the background prevalence rate, with the highest prevalence rates on the globe observed in South Africa and neighbouring countries, leading to high prevalence rates within firms. This creates clear(er) incentives for firms to provide workplace programmes not only due to the fact that such a high proportion of the workforce is HIV positive, but also because there is a smaller pool of workers that could potentially replace them. Therefore, these conditions are to some extent conducive to incentivising a positive, rather than negative, corporate response. However, this creates a paradox in which the business case holds for workers in areas in which HIV prevalence is high but worker's bargaining power is also higher, with the business case less compelling (and lower incentives to implement workplace programmes) in countries/regions and sectors where there is lower background prevalence where HIV positive workers are more replaceable and thus require more support in maintaining and accessing employment than workers in high prevalence countries and sectors. 


\section{Conceptual and Methodological Limitations}

The cost-benefit analysis approach which underpins the business case also suffers from some methodological and conceptual limitations that cast further doubt on the compelling nature of the evidence. These are related to well known critiques of the neoclassical theory of the firm upon which the economic modelling is based, such as the notion of the representative firm, the relationship between wages and marginal productivity and the assumptions about the inner workings of the firm, and, beyond recent developments within the neoclassical literature such as moral hazard and the principal-agent problem, financial structure and how decisions are made internally within a firm (Hart, 2011), the inner workings of firms remains to a great extent a black box. These shortcomings obscure the degree of heterogeneity between firms, presents a stylised and inaccurate view of the way that firms operate, and also results in questionable assumptions related to the quantification of costs that are required as inputs to the cost-benefit model.

\subsection{Heterogeneity of firms}

The degree to which the business case supports the introduction of workplace programmes by employers is mediated by several dimensions, primarily the skill level of infected workers, the sector of the firm, the size of the enterprise, and the firm level and background prevalence of HIV (which are intimately linked) (Johnston, 2013). In relation to the skill level of workers, the economic 'cost' of an HIV positive worker varies greatly by their skill level, with the benefits (costs avoided) of workplace programmes far greater for skilled workers and management than for unskilled workers (Rosen, et al., 2007). Indeed, in some cases, the business case for intervening in this positive manner is completely undermined. Rosen et al (2007) calculate that for an agricultural company in Kenya, the net benefit of an employer-sponsored treatment programme per employee was $-\$ 673$ per skilled worker and $-\$ 2278$ per unskilled worker (compared to $+\$ 17,999$ per manager), suggesting that the programme was not cost effective when applied to lower skilled workers, and overall, due to the employment composition of the company, the programme was costly for the company as a whole.

Indeed, it is unsurprising that most of the positive case studies originate from sectors such as mining, finance, manufacturing and other sectors that predominantly employ skilled workers (Brink \& Pienaar, 2007; Eholie, et al., 2003; Law, 2008; Meyer-Rath, et al., 2015; Oppenheimer, 2007; Setswe, 2009; UNAIDS, 2002), with studies that focus on the agricultural sector much less common. Further, the mining sector in particular dominates the literature, with around a third of best-practice workplace programmes originating from this sector (Setswe, 2009). Of course, this reflects not just the business case that has been made for positive intervention in this sector, but the role that the 
mining sector has played in the spread and intensification of the epidemic (Campbell, 1997, 2003; Crush, Williams, Gouws, \& Lurie, 2005; Hargrove, 2008; Law, 2008) which has provided additional social and political impetus for corporate engagement.

A third key dimension is firm size, with evidence suggesting that large firms are far more likely to implement workplace programmes or enact a formal HIV policy than medium size and small firms (Bolton, 2008; Ellis, 2006; Ramachandran, et al., 2007; Rosen, et al., 2007), in part because HIV is either not an issue for small and medium firms who recruit more informally and thus may not have many HIV positive workers (or are more likely to avoid hiring them) (Coetzee, 2003), and also due to their inability to make expensive and costly investments in their workforce. Small firms also may not face a strong imperative to present a positive public profile for external investors or shareholders.

The evidence also suffers from severe limitations arising from a narrow focus on categories of employment that do not reflect the employment experiences of the vast majority of HIV positive individuals. For example, in the Tanzania stigma index country assessment, fewer than $10 \%$ of the HIV positive respondents who participated in the survey were in full time employment, with the vast majority either working full or part time in self-employed/casual work (NACOPHA, 2013), with similar employment patterns reported in Zambia and Kenya (Sprague, et al., 2011). The business case approach fails to account for the many workers who are on temporary and casual contracts, as they frequently do not qualify for access to treatment programmes or company benefits, though in rare occurrences workplace programmes have been extended to cover suppliers and other workers in the supply chain. Further omissions from the business case approach are workers in the informal sector who are simply overlooked and out of scope (Vearey, Richter, Núñez, \& Moyo, 2011), and an incorporation of the gendered implications of the corporate response, pertinent due to the highly gendered nature of informal and casual/temporary labour (Gideon, 2012). We do not know if selfemployed, casual, temporary workers have anything to benefit from a business response to HIV because the business case literature is not concerned with these workers. There is evidence from the evaluation of other ethical codes that corporate social responsibility (CSR) initiatives often exclude workers on temporary contracts, and that those workers are likely to be women (Tallontire, Dolan, Smith, \& Barrientos, 2005). We add that other forms of disadvantage, such as being a migrant or a worker from an ethnically-discriminated group, are also likely to be relevant.

Overall then, the business case made in the literature is generally at odds with the lived experiences and conditions of much of the (potential) workforce and the broader employment dynamics for the general population in sub-Saharan Africa, in which casual/temporary employment and own-account employment, viewed as vulnerable employment, account for the vast majority of 
the labour force (ILO, 2014). This casts doubt on the viability and potential scope of the positive response, and indeed the ability for workplace programmes to achieve their stated objectives.

\subsection{Critiques of the cost-benefit analysis approach}

The framing of this issue within an approach that quantifies the economic impact of the epidemic on firms is also problematic in terms of the way that economic cost-benefits models are constructed, as well as the view that these models take on the way that firms function. In this sense firms are portrayed as profit maximising entities that weigh up the costs and benefits of different courses of action, producing rational and reasoned responses based on the calculated impact these different responses have on the firm's profitability. However, most of the models, as acknowledged by Rosen et al. (2007) fail to combine a full analysis of both costs and benefits identified above. Therefore, most of these cost-benefit analyses omit, or do not engage with, the possibility that firms may take action to remove or reduce the costs of employing HIV positive workers through the mechanisms outlined below. For example, it may be far more cost-effective to implement a pre-employment testing programme designed to exclude HIV positive workers than it would be to pay for treatment for a new HIV positive employee, and evidence exists to suggest that this happens; in a survey of firms in East Africa reported that in Uganda, Tanzania and Kenya, the proportion of firms conducting a pre-employment health check was 19.7\%, 51.9\% and 34.5\% respectively (Ramachandran, et al., 2007), despite the fact that pre-employment screening and hiring workers on the condition that they are not HIV positive clearly contravenes national anti-discrimination policies (Kassile, Anicetus, Kukula, \& Mmbando, 2014). However, despite evidence of firms behaving badly and the discrimination suffered by both HIV positive workers and those unemployed, few, if any, of the costbenefit analysis models incorporate the possibility that burden shifting behaviour could take place (for example (Eholie, et al., 2003; Ilon, et al., 2007; Rosen, et al., 2007). The lack of integration of the burden-shifting strategies into these models thus produces evidence that is incomplete and does not reflect the full range of strategies that are available to firms, nor the fact that firms are likely to employ a range of 'overlapping and sometimes incompatible strategies' (Dickinson \& Innes, 2004). Indeed, it is clear that the positive response and burden shifting strategies are not mutually exclusive, although to date they have been treated separately within the literature, further emphasising the limited and narrow way that this issue is treated within the cost-benefit framework.

Further, the notion of the firm as a rational decision maker is also questioned by the limited response to the funding of ARV provision by many sub-Saharan African governments from the early 2000s (for example, Tanzania from 2004 onwards, Zambia from 2005 onwards (WHO, 2005)), as 
noted above. Whilst ARV supplies are sometimes interrupted and future commitments to continue free provision are reliant on external funding, overall free ARV provision should have made a significant dent in the costs of workplace programmes, with theory predicting a subsequent expansion of workplace programmes as firms react to changes in the (reduced) costs of implementing them. However, despite these reduced costs, this has not been forthcoming, with workplace programme coverage remaining limited.

The business case approach can also be critically appraised on a methodological basis, particularly as it rests on the accurate estimation of the HIV-related costs. One significant cost is increased absenteeism of HIV positive workers due to sickness and attendance at clinics, which is measured in a number of ways, such as the daily average wage rate for that worker adjusted by a wage multiplier to capture firm level output impacts (Rosen, et al., 2004), or the wages of the replacement worker whilst at the same time continuing to pay the absent worker if they qualify for sick pay (Eholie, et al., 2003; Morris, Burdge, \& Cheevers, 2000). These costs are often presented as being estimated conservatively, as authors understandably seek to ensure that their results are robust and any significant economic impacts are not down to any exaggeration in the way that costs are quantified. However, the response of firms to absenteeism will vary widely depending on the structure of employment contracts, and the type of work the employee is doing. For example, there will be a difference in the direct costs of absenteeism between employment contracts where workers are paid a daily wage rate compared to employment conditions where workers are paid based on measurable targets, such as the daily quantity of tea plucked (Fox et al., 2004) in which employers do not incur direct wage costs if workers are absent. Further, firms will employ other coping strategies, such as putting more pressure on existing workers to take on the responsibilities of their colleagues, thus reducing the economic costs of the absent workers. A related and overlapping issue is how HIV related morbidity impacts individual and firm level productivity. This, as noted above, is in part included in the absenteeism costs, but is also quantified separately for workers that attend work but are unable to work at full capacity as a fraction of a day wage rate (Rosen, et al., 2004). As with the issue of absenteeism, the impact on overall productivity will depend on how the production process is organised and the degree to which workers are already working at full capacity and whether other workers can pick up the slack. However, in standard economic models, it is assumed that workers are working at full capacity, and so these issues remain unaccounted for.

There are also other perceived costs, such as decreased worker morale and teamwork, as a result of both high labour turnover and increased morbidity and mortality rates amongst HIV positive colleagues, leading to reduced productivity (Bennell, 2002). Whilst there has not been an 
attempt to quantify these more intangible costs (as far as the authors are aware), the impact on worker morale will vary by the degree to which workers compete or cooperate with each other in the workplace, how dependant workers tasks are on other workers, and the level of HIV stigma that exists. Indeed, if stigma against HIV positive workers within the workplace is high (as has been reported) this may lead to increased team coherence and morale if they are absent or are managed out of the firm.

A final issue is how the costs of absenteeism in the form of the daily wage rate for senior managers who are not directly involved in the production process, but who will have high daily wage rates. Production operations may be able to run as normal in the absence of senior management, who can catch up on work once they return as work for senior management is far more fluid than for workers on the production line, and so these costs may be significantly overinflated. The economic 'cost' of senior managers taking time out of the working day to go to clinics or have treatment may also be negligible compared to lower skilled workers who are needed for specific roles in the production process. Indeed, the absence of a senior manager leading to a quantifiable cost is in part rooted in assumptions within neoclassical theory that equate wages with contributions to value creation and productivity, though the role of management in these processes have often been questioned (Marglin, 1974). This casts further doubt on the validity of the business case approach, and perhaps, by significantly overstating the value of senior managers' and skilled workers' contribution to the production process.

The result is evidence that is highly skewed towards supporting positive action. Bearing in mind that the economic costs are often reported to be moderate even when the evidence is constructed to produce a positive business case, it is entirely possible that the business case might be undermined entirely if the cost-avoidance strategies are incorporated. This is especially pertinent for the dynamic situation, in which firms can seek to minimise future costs by avoiding hiring HIV positive workers, rather than the static case when firms are suddenly faced with an epidemic that has already infected members of their workforce. Whilst it has been suggested that firms cannot completely attempt to shift the burden and protect themselves from any impact by not engaging positively with the epidemic (Dickinson \& Innes, 2004), their ability to do so will be influenced by the dimensions noted above.

A more nuanced understanding, drawing on a political economy approach that incorporates the notion of the labour process and a focus on how firms (and work) are organised enables a reflection on other aspects of the business-case approach. For example, the gatekeepers and implementers of workplace programmes and HIV policies designed to reduce the economic impact of the epidemic are often lower level management and supervisors, rather than senior management. 
How company policies are implemented by this layer of lower management are crucial to their success. As Scott et al. (2013) note, supervisors and lower level managers may have other imperatives and may not understand the overall benefits of ensuring that workers have time to take their drugs or go to the clinic, and that this can lead to uneven implementation, sometimes reliant on the attitudes towards the issue of individual supervisors (Scott, et al., 2013). Whilst their recommendations to improve this include better training for supervisors on company policy, they also acknowledge that lower level managers are under significant pressure to deliver results and hit targets. This mixed and sometimes obstructive attitude towards supporting HIV positive workers results from the logic of this pressure, and the role that refusing or controlling time off to take ARV's or go the clinic can play in terms of disciplining both individual workers and the workforce as a whole, helping to cement existing power relations between supervisors and workers.

The poor uptake of some workplace programmes in terms of VCT services and support with ART can be explained by the fact that employees are frequently not comfortable with management being aware of their status, especially if this knowledge can be used by management in coercive ways. Further, recent evidence illustrates other forms of abuse suffered by workers at the hands of immediate supervisors, including sexual harassment (Cramer, Johnston, Oya, \& Sender, 2014), emphasising that this relationship is problematic for a range of reasons that go beyond lack of understanding and awareness. Within the literature on the corporate response to the epidemic, this relation is one that requires further unpacking.

Finally, the ongoing stigma that workers encounter from colleagues and management can also have a negative impact on treatment adherence in settings where workers who have not disclosed their status miss ARV doses in attempts to hide their ARV use from other workers (ILO2013), with the ILO acknowledging that 'employment can negatively impact on ART adherence in both informal and formal work settings' (ILO 2013).

\section{Towards a future research agenda}

The limitations of the business case approach, in part due to the micro-economic underpinnings, the failure for cost-benefit analyses to account for the wide range of different strategies that firms may employ, and the disjuncture between the situations in which the business case holds and the employment experience of the majority of the sub-Saharan African population, suggests that this issue is both under-researched and poorly understood. There are both significant evidence gaps, as well as a range of methodological challenges related to pursuing research on this topic.

The evidence, particularly in relation to the burden shifting that firms employ, is sparse, fragmented, and often anecdotal. Rosen and Simon (2003) present a summary of evidence, both 
anecdotal and from several surveys conducted with firms in South Africa, that illustrate the different ways in which firms employ this strategy. For example, they report that a firm in Botswana reduced the number of sick days that their employees were able to take, and an anonymous logistics company terminated the contracts of its drivers and subsequently rehired them as 'owneroperators' thus shifting any HIV associated costs onto the now self-employed 'entrepreneurs'. Rosen and Simon also discuss survey evidence from a survey conducted by Old Mutual, a South African services firm, in which $78 \%$ of 56 firms in the sample said that they had restructured healthcare benefits (ibid). A World Bank survey in 1999 of 325 firms in the Johannesburg area found that $40 \%$ of firms reported hiring fewer workers, using more temporary workers and more machinery. Other evidence originates from the People Living HIV (PLHIV) Stigma Index surveys. PLHIV Stigma index surveys in Kenya (2009) and Zambia (2010) show that 40\% of PLHIV had lost a job in the last 12 months, with the majority reporting that this was entirely or partly due to their HIV status, and 25 percent had been refused a promotion or had their job title changed (Sprague, et al., 2011). Further, of those out of work, 24\% (Kenya) and 36 percent (Zambia) reported that they had been denied employment due to their HIV status, and in Tanzania, between 20 percent and 30 percent of PLHIV in the 2013 stigma index survey reported having lost a job or a source of income due to their HIV status (NACOPHA, 2013).

There are also serious methodological challenges when trying to investigate how employers have responded to the epidemic. In particular, the limited numbers of studies that have addressed this issue have relied upon privileged access to sensitive firm data, implying a degree of cooperation with the firm. This has, perhaps, influenced the lines of enquiry, and may explain why these case studies do not seem to address the possibility that these firms have used other less supportive strategies in their response, and also the dearth of studies (beyond the anecdotal evidence noted above) that seek to understand the full array of strategies. However, any future research will depend on the cooperation of the firms under investigation, be it to provide sensitive data or facilitate access to workers, and the ability of researchers to resist attempts by management to influence the research process (Kenworthy, 2014).

A further issue relates to the challenge of disentangling firms responses to the epidemic from responses to the broader socio-economic context (Rosen, et al., 2007). For example, the casualisation of labour markets may reflect both a shifting of the burden from employers to workers, and must be understood within the broader context of increasing casualisation of work driven by economic liberalisation and the neoliberal policy agenda in sub-Saharan Africa. Ascribing causality in this instance is difficult, and indeed it is entirely possible that firms would have proceeded with casualisation in the absence of the epidemic as in other parts of the world, though the HIV epidemic 
could have intensified the pace of casualisation. Nonetheless, processes of change in capitalist systems of production have meant that the social costs of reproduction are increasingly shouldered by households, especially by women within them, as the state and private sector fail to provide care and support (Akintola, 2004; Johnston, 2008; O'Laughlin, 2013). These processes have specific implications on the ways in which the HIV epidemic is dealt with that need to be further investigated. More evidence is needed to document how firms' engagement with the epidemic has varied over time.

Finally, in some cases contract structures and hiring practices already implicitly discriminate against HIV positive workers or will lead to a degree of self-(de)selection. For example, contracts in which workers are paid by the amount of work done (piece work), rather than a standard wage rate, will lead to lower incomes and a higher degree of fragility of employment. Hiring practices for informal employment in which workers are hired and rehired on a daily basis also make it more difficult for workers who need time off to access employment, as this gives the impression that they are unreliable. These hiring practices are widespread, arising from the seasonal nature of most work and the desire of employers to keep costs low (Oya \& Sender, 2009) and further muddies the water in terms of how the response of employers is framed and understood.

The emphasis on trying to provide a business case also belies the fact that the corporate response is influenced by a range of other internal and external factors, and is not necessarily the dominant factor when accounting for firms' decisions, often an ex-post justification for a specific course of action (Dickinson \& Stevens, 2005). The incorporation of workplace programmes into CSR strategies and the requirements of specific industries to cultivate an image as a responsible social actor, internal champions that may have a personal stake in the issue of HIV and thus promote HIV as an important issue for firm engagement, the degree to which HIV is viewed as a priority, and the strength of external legislative regimes, also influence how firms respond (Bakuwa \& Mamman, 2012; Dickinson \& Innes, 2004; Dickinson \& Stevens, 2005; Harinarain \& Haupt, 2014). These all need to be accounted for in future research that must be rooted in theoretical approach that is better able to engage with these multiple range of issues, and to move beyond simplistic and narrow costbenefit analyses.

\section{Conclusion}

The evidence reviewed above illustrates that, contrary to the claims made by visible proponents of workplace programmes, the business case for positive workplace interventions is weak, frequently overstated, and does not hold for the types of employment that most workers in sub-Saharan Africa engage in. This is due to the fact that the costs of employing and support HIV positive workers is 
influenced by a range of dimensions, including firm size, sector, firm level and background prevalence rates, and the skill level of the workforce. This suggests that the win-win scenario highlighted above is wishful thinking on the part of those advocating the introduction of workplace programmes as good for both businesses and workers. The patchy and unequal implementation of supportive workplace programmes, reflective of fragmented legislative regimes (Harinarain \& Haupt, 2014), which prioritise senior management and skilled workers in leading sectors, also serves to continue to embed health inequalities in a systemic manner (Bridget O'Laughlin, 2016). The business case may be further undermined if other strategies that firms use to mitigate the impact of the epidemic, which have been explored under the notion of shifting the burden, are incorporated into cost-benefit analyses. Whilst assumptions over how to quantify the economic impact are necessary, these can also be re-examined in the light of alternative conceptions of the firm that focus on the labour process and the dynamics of production and accumulation, further undermining the case for a positive corporate response.

The preceding debate has implications for how this agenda is taken forward. In the light of the expanding role for the private sector in addressing global health to the detriment of state participation, the literature has taken the approach that firms should be encouraged to do the right thing by showing that positive courses of action are good for business. If the business case does not hold, then the implantation of workplace programmes is largely reliant on emerging forms of 'philanthrocapitalism' (O'Laughlin, 2016) to take on this agenda. This serves to undermine state involvement in the provision of HIV testing services and treatment, and it is questionable whether employers can be relied upon to fulfil this role. An alternative approach would be for policy makers to compel firms to support HIV workers through the implementation and enforcement of industry regulations designed to provide an appropriate level of support as well as enhanced and enforceable employment rights for HIV positive workers across all sectors. Further, the extent to which the workplace should even be considered as an appropriate site for HIV related interventions is questionable, especially as HIV programmes can come to dominate interventions aimed at employees and detract attention from other concerns that workers have such as low wages and poor working conditions (Kenworthy, 2014). Whilst it is not suggested that firms are given free range to abdicate their responsibilities to workers and local communities, nor that workplace programmes cannot in some settings enhance access to treatment for HIV positive workers, there is a need for a rethink of how best to support HIV positive workers, and the mechanisms through which to do this, which should include strengthening public healthcare systems in sub-Saharan Africa. However, our review has demonstrated that the positive review of a private sector-led response to HIV in subSaharan Africa is at least questionable, if not entirely misplaced. 


\section{References}

Abrahams, N., \& Jewkes, R. (2012). Managing and resisting stigma: a qualitative study among people living with HIV in South Africa (Vol. 15).

AIDS Accountability International, \& Rosencrantz and Co. (2011). Responding to HIV and AIDS: Good practices for investors and businesses. London: CDC, DFID.

Akintola, O. (2004). A Gendered Analysis of the Burden of Care on Family and Volunteer Caregivers in Uganda and South Africa. Health Economics and HIV/AIDS Research Division (HEARD.

Durban. Retrieved from http://www.sarpn.org/documents/d0001119/P1241-

Akintola_August2004.pdf

Ann Richey, L. (2012). Counselling citizens and producing patronage: AIDS treatment in South African and Ugandan clinics. Development and Change, 43, 823-845.

https://doi.org/10.1111/j.1467-7660.2012.01782.x

Bakuwa, R., \& Mamman, A. (2012). Factors hindering the adoption of HIV/AIDS workplace policies: evidence from private sector companies in Malawi. The International Journal of Human Resource Management, 23, 2917-2937. https://doi.org/10.1080/09585192.2012.671511

Bendell, J. (2003). Waking Up to Risk: Corporate Responses to HIV/AIDS in the Workplace. UNRISD Programme on Technology, Business and Society. Geneva.

Bennell, P. (2002). Hitting the target: Doubling primary school enrollments in sub-Saharan Africa by 2015. World Development, 30, 1179-1194. https://doi.org/10.1016/S0305-750X(02)00027-X

Boesten, J. (2011). Navigating the AIDS industry: Being poor and positive in Tanzania. Development and Change, 42, 781-803. https://doi.org/10.1111/j.1467-7660.2011.01713.x

Bolton, P. L. (2008). Corporate responses to HIV/AIDS: Experience and leadership from South Africa. Business and Society Review, 113, 277-300. https://doi.org/10.1111/j.14678594.2008.00321.x

Brink, B., \& Pienaar, J. (2007). Business and HIV/AIDS: the case of Anglo American. AIDS, 21, S79-S84. https://doi.org/10.1097/01.aids.0000279697.40568.fd

Bujra, J. (2004). AIDS as a crisis in social reproduction. Review of African Political Economy, 31(102), 631-638. https://doi.org/10.1080/0305624042000327787

Campbell, C. (1997). Migrancy, masculine identities and AIDS: The psychosocial context of HIV transmission on the South African Gold Mines. Social Science and Medicine, 45(2), 273-281.

Campbell, C. (2003). Letting Them Die. Oxford: James Currey. 
Coetzee, C. (2003). Hiring Patterns, Firm-Level Dynamics and HIV/AIDS: A Case Study of Small Firms on the Cape Flats. Cape Twon: Centre for Social Science Research, University of Cape Town.

Cohen , M. S., Chen , Y. Q., McCauley , M., Gamble , T., Hosseinipour , M. C., Kumarasamy, N., et al. (2011). Prevention of HIV-1 Infection with Early Antiretroviral Therapy. New England Journal of Medicine, 365(6), 493-505. https://doi.org/10.1056/NEJMoa1105243

Connelly, P., \& Rosen, S. (2008). Treatment for HIV/AIDS at South Africa's largest employers: myth and reality. South African Medical Journal, 96(2).

Cramer, C., Johnston, D., Oya, C., \& Sender, J. (2014). Fairtrade, Employment and Poverty Reduction in Ethiopia and Uganda. Final Report to DFID, April 2014. FTPER, SOAS. London.

Cramer, C., Oya, C., \& Sender, J. (2008). Lifting the blinkers: a new view of power, diversity and poverty in Mozambican rural labour markets. The Journal of Modern African Studies, 46, 361-392. https://doi.org/10.1017/S0022278X08003340

Crush, J., Williams, B., Gouws, E., \& Lurie, M. (2005). Migration and HIV/AIDS in South Africa. Development Southern Africa, 22, 293-318.

Dickinson, D., \& Innes, D. (2004). Fronts or front-lines? HIV/AIDS and big business in South Africa. Transformation: Critical Perspectives on Southern Africa, 55, 28-54.

Dickinson, D., \& Stevens, M. (2005). Understanding the response of large South African companies to HIV/AIDS. Journal of Social Aspects of HIV/AIDS, 2, 286-295.

dos Santos, M. M., Kruger, P., Mellors, S. E., Wolvaardt, G., \& van der Ryst, E. (2014). An exploratory survey measuring stigma and discrimination experienced by people living with HIV/AIDS in South Africa: the People Living with HIV Stigma Index. [journal article]. BMC Public Health, 14(1), 80. https://doi.org/10.1186/1471-2458-14-80

Eholie, S., Nolan, M., Gaumon, A., Mambo, J., Kouam-Yebouet, Y., Aka-Kakou, R., et al. (2003). ART can be cost-saving for industry and life-saving for workers: A case study from Côte d'Ivoire's private sector. Economics of AIDS and access to HIV/ AIDS care in developing countries: issues and challenges. Paris: Agence Nationale de Recherches sur le Sida.

Ellis, L. I. (2006). The economic impact of HIV/AIDS on small, medium and large enterprises. South African Journal of Economics, 74, 682-701. https://doi.org/10.1111/j.18136982.2006.00093.x

Fox, M. P., Rosen, S., MacLeod, W. B., Wasunna, M., Bii, M., Foglia, G., et al. (2004). The impact of HIV/AIDS on labour productivity in Kenya. Tropical Medicine \& International Health, 9, 318324. https://doi.org/10.1111/j.1365-3156.2004.01207.x 
George, G. (2006). Workplace ART programmes: Why do companies invest in them and are they working? African Journal of AIDS Research, 5, 179-188. https://doi.org/10.2989/16085900609490378

Gideon, J. (2012). Engendering the health agenda? Reflections on the Chilean case, 2000-2010. Social Politics, 19, 333-360.

Gideon, J., \& Porter, F. (2016). Unpacking 'women's health' in the context of PPPs: A return to instrumentalism in development policy and practice? Global Social Policy, 16(1), 68-85. https://doi.org/10.1177/1468018115594650

Habyarimana, J., Mbakile, B., \& Pop-Eleches, C. (2010). The impact of HIV/AIDS and ARV treatment on worker absenteeism: Implications for African firms. Journal of Human Resources, 45, 809839. https://doi.org/10.3368/jhr.45.4.809

Hargrove, J. (2008). Migration, mines and mores: the HIV epidemic in southern Africa. [Article]. South African Journal of Science, 104(1/2), 53-61.

Harinarain, N., \& Haupt, T. C. (2014). Drivers for the effective management of HIV and AIDS in the South African construction industry - a Delphi study. African Journal of AIDS Research, 13, 291-303. https://doi.org/10.2989/16085906.2014.952653

Hart, O. (2011). Thinking about the firm: A review of Daniel Spulber's The Theory of the Firm. Journal of Economic Literature, 49(1), 101-113. https://doi.org/10.1257/jel.49.1.101

Hunsmann, M. (2016). Pushing 'global health' out of its comfort zone: Lessons from the depoliticization of AIDS control in Africa. Development and Change, 47, 798-817. https://doi.org/10.1111/dech.12241

ILO. (2013). The Impact of Employment on HIV treatment and adherence. ILO: Geneva

ILO. (2014). Global Employment Trends 2014: Risk of a jobless recovery? ILO: Geneva.

ILO. (2015). Effective responses to HIV and AIDS at work: A multi-country study in Africa. Geneva: International Labour Office, HIV and AIDS and the World of Work Branch.

Ilon, L., Barwise, K., Hüsken, S., \& Tembo, M. (2007). Cost Benefit Analysis of HIV Workplace Programmes in Zambia. Lusaka: Comprehensive HIV AIDS Management Programme (CHAMP), Zambia.

Johnston, D. (2008). Bias, not error: Assessments of the economic impact of HIV/AIDS using evidence from micro studies in sub-Saharan Africa. Feminist Economics, 14(4), 87-115. https://doi.org/10.1080/13545700802262915

Johnston, D. (2013). Economics and HIV: The Sickness of Economics. Abingdon: Routledge. 
Kassile, T., Anicetus, H., Kukula, R., \& Mmbando, B. P. (2014). Health and social support services to HIV/AIDS infected individuals in Tanzania: employees and employers perceptions. BMC Public Health, 14(1), 1-9. https://doi.org/10.1186/1471-2458-14-630

Kenworthy, N. J. (2014). A manufactu(RED) ethics: Labor, HIV, and the body in Lesotho's "sweatfree" garment industry. Medical Anthropology Quarterly, 28, 459-479. https://doi.org/10.1111/maq.12114

Kironde, S., \& Lukwago, J. (2002). Corporate response to the HIV/AIDS epidemic in Uganda - time for a paradigm shift? African Health Sciences, 2(3), 127-135.

Knutsson, B. (2016). Responsible risk taking: The neoliberal biopolitics of people living with HIV/AIDS in Rwanda. Development and Change, 47, 615-639. https://doi.org/10.1111/dech.12227

Law, D. (2008). Positive corporate responses to HIV/AIDS: a snapshot of large cap South African companies: EIRIS Foundation.

Macklin, R., \& Cowan, E. (2012). Given financial constraints, it would be unethical to divert antiretroviral drugs from treatment to prevention. Health Affairs, 31, 1537-1544. https://doi.org/10.1377/hlthaff.2012.0071

Mahajan, A. P., Colvin, M., Rudatsikira, J.-B., \& Ettl, D. (2007). An overview of HIV/AIDS workplace policies and programmes in southern Africa. AIDS, 21(Suppl 0), S1-S9.

Marglin, S. A. (1974). What do bosses do? The origins and functions of hierarchy in capitalist production. Review of Radical Political Economics, 6(2), 60-112. https://doi.org/10.1177/048661347400600206

May, M. T., Gompels, M., Delpech, V., Porter, K., Orkin, C., Kegg, S., et al. (2014). Impact on life expectancy of HIV-1 positive individuals of CD4+ cell count and viral load response to antiretroviral therapy. AIDS, 28, 1193-1202. https://doi.org/10.1097/qad.0000000000000243

Meyer-Rath, G., Pienaar, J., Brink, B., van Zyl, A., Muirhead, D., Grant, A., et al. (2015). The impact of company-level ART provision to a mining workforce in South Africa: A cost-benefit analysis. PLoS Med, 12(9). https://doi.org/10.1371/journal.pmed.1001869

Mills, E. J., Bakanda, C., Birungi, J., Chan, K., Ford, N., Cooper, C. L., et al. (2011). Life expectancy of persons receiving combination antiretroviral therapy in low-income countries: A cohort analysis from Uganda. Annals of Internal Medicine, 155, 209-216. https://doi.org/10.7326/0003-4819-155-4-201108160-00358

Morris, C. N., Burdge, D. R., \& Cheevers, E. J. (2000). Economic impact of HIV infection in a cohort of male sugar mill workers in South Africa. South African Journal of Economics, 68, 413-419. https://doi.org/10.1111/j.1813-6982.2000.tb01286.x 
Mueller, B. E. T. (2011). The agrarian question in Tanzania: Using new evidence to reconcile an old debate. Review of African Political Economy, 38(127), 23-42. https://doi.org/10.1080/03056244.2011.552589

NACOPHA. (2013). PLHIV Stigma Index Tanzania Country Assessment. Dar Es Salaam: National Council of People Living With HIV and AIDS in Tanzania (NACOPHA).

Nguyen, V.-K., Bajos, N., Dubois-Arber, F., O'Malley, J., \& Pirkle, C. M. (2011). Remedicalizing an epidemic: from HIV treatment as prevention to HIV treatment is prevention. AIDS, 25, 291293. https://doi.org/10.1097/QAD.0b013e3283402c3e

O'Laughlin, B. (2013). Land, labour and the production of affliction in rural Southern Africa. Journal of Agrarian Change, 13(1), 175-196.

O'Laughlin, B. (2016). Pragmatism, structural reform and the politics of inequality in global public health. Development and Change, 47, 686-711. https://doi.org/10.1111/dech.12251

Oppenheimer, J. (2007). Business and AIDS in South Africa. AIDS, 21, S11-S12. https://doi.org/10.1097/01.aids.0000279689.31158.66

Oya, C., \& Sender, J. (2009). Divorced, separated, and widowed women workers in rural Mozambique. Feminist Economics, 15(2), 1-31. https://doi.org/10.1080/13545700902729516

Ramachandran, V., Shah, M. K., \& Turner, G. L. (2007). Does the private sector care about AIDS? Evidence from firm surveys in East Africa. AIDS, 21, S61-S72. https://doi.org/10.1097/01.aids.0000279695.55815.de

Rosen, S., Feeley, F., Connelly, P., \& Simon, J. (2007). The private sector and HIV/AIDS in Africa: taking stock of 6 years of applied research. AIDS, 21, S41-S51. https://doi.org/10.1097/01.aids.0000279693.61652.2d

Rosen, S., Larson, B., Rohr, J., Sanne, I., Mongwenyana, C., Brennan, A. T., et al. (2014). Effect of antiretroviral therapy on patients' economic well being: Five-year follow-up. AIDS, 28, 417424. https://doi.org/10.1097/qad.0000000000000053

Rosen, S., \& Simon, J. L. (2003). Shifting the burden: the private sector's response to the AIDS epidemic in Africa. Bulletin of the World Health Organization, 2003(81), 131-137.

Rosen, S., Vincent, J. R., MacLeod, W., Fox, M., Thea, D. M., \& Simon, J. L. (2004). The cost of HIV/AIDS to businesses in southern Africa. AIDS, 18, 317-324.

Scott, K., Campbell, C., Skovdal, M., Madanhire, C., Nyamukapa, C., \& Gregson, S. (2013). What can companies do to support HIV-positive workers? Recommendations for medium- and largesized African workplaces. International Journal of Workplace Health Management, 6(3), 174-188. https://doi.org/10.1108/IJWHM-12-2010-0043 
Setswe, G. K. G. (2009). Best practice workplace HIV/AIDS programmes in South Africa: A review of case studies and lessons learned. African Journal of Primary Health Care \& Family Medicine, 1(1).

Simon, J. L., Rosen, S., Whiteside, A., Vincent, J. R., \& Thea, D. M. (2000). The Response of African Businesses to HIV/AIDS HIV/AIDS in the Commonwealth 2000/01. London: Kensington Publications.

Sprague, L., Simon, S., \& Sprague, C. (2011). Employment discrimination and HIV stigma: survey results from civil society organisations and people living with HIV in Africa. African Journal of AIDS Research, 10(sup1), 311-324. https://doi.org/10.2989/16085906.2011.637730

Tallontire, A., Dolan, C., Smith, S., \& Barrientos, S. (2005). Reaching the marginalised? Gender value chains and ethical trade in African horticulture. Development in Practice, 15, 559-571. https://doi.org/10.1080/09614520500075771

UNAIDS. (2002). The private sector responds to the epidemic: Debswana-a global benchmark UNAIDS Best Practice Collection. Geneva: UNAIDS.

UNAIDS. (2014). 90-90-90: An ambitious treatment target to help end the AIDS epidemic. UNAIDS. Geneva.

Vass, J. (2003). Impact of HIV/AIDS on the labour force, exploring vulnerabilities. CODESRIA Bulletin, Speical Issue.

Vearey, J., Richter, M., Núñez, L., \& Moyo, K. (2011). South African HIV/AIDS programming overlooks migration, urban livelihoods, and informal workplaces. African Journal of AIDS Research, 10(sup1), 381-391. https://doi.org/10.2989/16085906.2011.637741

WHO. (2005). Countries offering free access to HIV treatment, Developing Countries \& Free Access Fact Sheet / December 2005, WHO

WHO. (2016). Antiretroviral therapy (ART) coverage among all age groups Retrieved from: http://www.who.int/gho/hiv/epidemic_response/ART_text/en/ 